\title{
Daily domain-specific time-use composition of physical behaviors and blood pressure
}

\author{
Nidhi Gupta ${ }^{1 *}$ DD, Mette Korsh $ø j^{1}$, Dorothea Dumuid ${ }^{2}$, Pieter Coenen ${ }^{3}$, Karen Allesøe $e^{4}$ and Andreas Holtermann ${ }^{1,5}$
}

\begin{abstract}
Background: Previous research has shown contrasting effects on hypertension for occupational and leisure-time physical behaviors - physical activity and sedentary behavior and time in bed. However, (a) none of these studies have addressed the compositional property of the physical behaviors and (b) most knowledge on the association between domain-specific physical behaviors and hypertension relies upon self-reported physical behaviors information primarily on white-collar worker study samples. We aimed to be the first to disentangle the relationship between technically measured 24-h time-use behaviors in work and leisure domains and blood pressure among blue-collar workers using a compositional data analysis approach.

Methods: Workers $(n=669)$ wore accelerometers to measure daily minutes of work and leisure sedentary time, light physical activity (LPA) and moderate-to-vigorous physical activity (MVPA), and time in bed which were isometrically log-transformed. Cross-sectional linear association between time-use composition and systolic (SBP) and diastolic (DBP) blood pressure were determined using compositional isotemporal substitutions models.

Results: The time-use composition at the work and leisure domains was significantly associated with SBP $(F=4.98, p<0.001)$ and $\mathrm{DBP}(\mathrm{F}=2.91, p=0.008)$. Reallocating sedentary time to remaining behaviors within each domain — work and leisure - was favorably associated with SBP. Similar results were observed when reallocating time in bed from the remaining leisure behaviors. Results for reallocating time to/from MVPA and LPA at both domains were non-significant. Results regarding all physical behaviors for DBP were generally non-significant.

Conclusions: Time-use composition of physical behaviors at work and leisure is associated with blood pressure among blue-collar workers. At both domains, reallocating sedentary time to remaining behaviors, especially to time in bed at leisure may reduce blood pressure. Our results, based on a compositional data approach, can be used to better design accurate and comprehensive time-use recommendations both at work and leisure for high-risk groups like blue-collar workers.
\end{abstract}

Keywords: Accelerometry, Domain, Sleep, Physical activity, Sedentary behaviors

\section{Background}

Hypertension is an established risk factor for cardiovascular diseases such as stroke [1] and myocardial infarction [1]. In 2015, 21\% of the global population was diagnosed with hypertension [2] and alarmingly, it may increase up to $60 \%$ by 2025 [3]. Therefore, knowledge of effective preventive strategies for hypertension is needed, especially among high-risk populations, such as bluecollar workers $[4,5]$.

\footnotetext{
* Correspondence: ngu@nfa.dk; ngu@nrcwe.dk

${ }^{1}$ National Research Centre for the Working Environment, Copenhagen, Denmark

Full list of author information is available at the end of the article
}

Physical behaviors such as standing, walking, and sedentary behavior are associated with blood pressure [6-8]. Research has shown elevated blood pressure among those who are sedentary [9] and/or physically inactive [10], which reduced among those breaking up their sedentary behavior [11] or being physically active [12]. Moreover, sleep duration that is too short or long has also been shown to increase the risk of hypertension [13].

Recent evidence suggests a contrasting effect of work and leisure physical behaviors on blood pressure $[5,7$, 14-17]. This might be explained by differences in intensity, duration, and frequency of activities at work and

(C) The Author(s). 2019 Open Access This article is distributed under the terms of the Creative Commons Attribution 4.0 International License (http://creativecommons.org/licenses/by/4.0/), which permits unrestricted use, distribution, and 
leisure [18]. In general, work physical activity is performed at lower intensities and for longer durations [18] than leisure physical activity. Thus, work physical activity may induce a higher total cardiovascular load without reaching sufficient intensity of physical activity to increase cardiorespiratory fitness, and with limited time and decision latitude to achieve sufficient recovery $[4,18]$ compared to leisure physical activity. Hence, it might be necessary to differentiate between work and leisure behaviors when investigating their association with blood pressure.

Time spent in physical behaviors during work, leisure and sleep constitute mutually exclusive components of the complete day (i.e., 24h). As such, it is impossible to increase time in one behavior without decreasing time in at least one other behavior within that day. Health impacts associated with an increase in one behavior may depend on which behavior it is replacing. The compositional nature of these data imposes important implications for statistical analysis and interpretation which has been addressed by very few studies only $[6,8,19,20]$, investigating the association with blood pressure. For example, one study using compositional data analysis found that reallocating sedentary time with time in bed and MVPA is beneficially associated with hypertension [8]. However, none of these studies have investigated if these associations differ when separating between work and leisure using a compositional data analysis (CoDA) approach. Therefore, there is a need to apply CoDA methodology to investigate the domainspecific association between physical activity and blood pressure.

Most previous studies on preventing hypertension have (a) used self-reported information of physical behaviors at work and leisure [17, 21, 22] which has shown to be inaccurate and biased [23, 24] (b) and/or are centered around the general population or whitecollar workers with little focus on lower socioeconomic position groups, like blue-collar workers. These blue-collar workers are generally exposed to high physical work demands (e.g. heavy lifting and static standing) which can increase blood pressure [5], while spending most leisure time (i.e, non-work time) being sedentary [25]. Thus, the 24-h physical behaviors profile for blue-collar workers can be very different from white-collar workers, mostly being sedentary at work and more physically active at leisure.

In this study, we aimed to investigate the association between technically measured physical behaviors during the work and leisure domain and blood pressure among blue-collar workers using a compositional data analysis approach.

\section{Methods}

This study is based on cross-sectional data from the Danish PHysical ACTivity cohort with Objective measurements (DPHACTO) that aims to determine the prospective association between technically measured physical behaviors at work and leisure and monthly measurements of musculoskeletal pain primarily among blue-collar workers (see more details here; 26). Workers from 15 Danish manufacturing, cleaning, and transport workplaces were recruited between 2011 and 2013. Workers were excluded if pregnant, had fever, or were allergic to adhesives. Details about the study protocol, recruitment, and inclusion and exclusion criteria can be found elsewhere [26]. Conducting and reporting of this study has been done in accordance to STROBE statement guidance (Additional file 2).

Of the 2107 eligible workers invited to participate, 1119 consented to participate. Workers were asked to fill in a web-questionnaire and participate in healthrelated tests and accelerometry. Cross-sectional data in DPHACTO were collected between 2012 and 2013.

\section{Measurement of daily work and leisure physical behaviors} Workers were instructed to attach a tri-axial Actigraph accelerometer (GT3X+, USA) on their right thigh for 24-h for four consecutive days. Simultaneously, workers were asked to fill-in a short diary noting the time they started and ended work, went and got out of bed, and time of reference measurement (i.e., standing in the upright position for $15 \mathrm{~s}$ ). Further details of measurements of physical behaviors have been provided elsewhere [27].

An Acti4 program was used to identify periods spent in various physical behaviors (i.e., sedentary behavior, walking slow and walking fast, running, cycling, and stair-climbing) [28]. A description of this program technically detecting time spent in each physical behavior is provided elsewhere [27, 28]. Time spent standing and slow walking was merged to calculate LPA, while fast walking, running, cycling and stair-climbing time was merged to calculate MVPA. Time in bed was defined as the period between going to and getting out of bed. Work period was defined as hours spent in primary occupation. Leisure period was defined as time within a day except for work time and time in bed.

All non-working days and accelerometer non-wear periods were excluded according to previously defined criteria [27]. Workers who had measurements of valid work, leisure and time in bed on at least one day were included in further analyses. Criteria of a valid work and leisure period and valid time in bed period are explained elsewhere [29]. 
For the analyses, the mean time spent sedentary, in LPA, and MVPA measured on all valid days and a median of all valid time in bed periods was calculated for each worker. We chose these statistics based on the distribution of the data.

\section{Systolic and diastolic blood pressure}

Resting blood pressure measurements were performed during working hours and on the first day of accelerometry. Workers were asked to rest in a seated position for five minutes with their back supported, legs uncrossed and arm supported. Blood pressure was measured on the left arm three times at regular 1-2-min intervals with the Omron M6 Comfort. The average of the last two recordings was used.

\section{Measurement of confounders}

Potential confounders were chosen a priori based on the literature on the association between physical activity and sedentary behavior and blood pressure $[30,31]$. Age and sex of the workers were determined using their unique civil registration number. Age was operationalized in two groups; $\leq 45$ years and $>45$ years. Body mass index (BMI) was determined by dividing objectively measured weight $(\mathrm{kg})$ by height squared $\left(\mathrm{m}^{2}\right)$, collapsing it into two categories: $<30$ $\mathrm{kg} / \mathrm{m}^{2}$ and $\geq 30 \mathrm{~kg} / \mathrm{m}^{2}$ [8]. Time spent lifting/carrying at work was determined using a single item with 6 responses ranging from 'almost all the time' to 'never' [27]. Workers were also asked if they take prescribed medication intake due to hypertension, depression and heart disease. Poor dietary intake was determined using a single item "How often do you usually eat Fastfood, pizza, burger, shawarma," with four responses from 'Every day' to 'Rare' [8]. Smoking status and alcohol intake information was collected using single items [8]. Information about the job sector of the workers was obtained from the payroll. Two items were used to determine influence at work [32] and another two to determine social support at work [32]. The responses for both variables were converted to a 0 to $100 \%$ scale where $0 \%$ indicates low influence at work or low social support at work $[8,32]$.

\section{Statistical analysis}

The statistical analyses were performed in R software (version 3.3.2; 2016-10-31) using the package 'Compositions' [33]. Because time-use data are compositional in nature, compositional data analysis (CoDA) was used [6, 34-36]. The first step was to express the time-use composition as a set of isometric log ratios (ilrs). The timeuse composition consisted of seven behaviors (work and leisure sedentary behavior, work and leisure LPA, work and leisure MVPA, and time in bed), resulting in six ilrs.

\section{Main analysis}

Multiple linear regression was used to determine the association between systolic blood pressure (SBP) or diastolic blood pressure (DBP) and the time-use composition (expressed as ilrs). First, these analyses were adjusted only for age and gender - crude model. Later, these analyses were further adjusted for BMI, smoking, alcohol intake, poor dietary intake, time spent lifting/carrying at work, and prescribed medicine intake adjusted model. To interpret the beta coefficients, compositional isotemporal substitution analyses were used [8]. The multiple linear regression models (adjusted models) were used to predict the difference in blood pressure for varying time reallocations among parts of the time-use composition. For this analysis, the sample mean composition was used as the reference or baseline composition. From there, the new compositions were generated by increasing/decreasing duration in one behavior and simultaneously taking out/distributing that duration equally from/to the remaining behaviors, to maintain a daily total of $1440 \mathrm{~min}$ following the procedure detailed elsewhere [8] also known as one-to-remaining reallocation. Because the number of working hours is generally fixed, we performed substitution models within each domain (work or leisure) instead of performing inter-domain reallocations. For example, sedentary time at work was incrementally decreased by $30 \mathrm{~min}$ while these $30 \mathrm{~min}$ were distributed equally to remaining behaviors at work while keeping the leisure behaviors constant. The differences in predicted blood pressure associated with the reallocation of time between behaviors were plotted to visually display the relationship between the predicted differences in blood pressure associated with a difference in each behavior relative to other behaviors within each domain. The $95 \%$ confidence intervals of the predicted differences in blood pressure corresponding to each reallocation were also calculated and are presented in Appendix A and Appendix B for SBP and DBP, respectively.

\section{Sensitivity analysis}

In the main analysis, we did not adjust for psychosocial work factors due to too many $(n=208)$ missing values in these variables. The missing values were due to a technical error that occurred while participants were answering the web-questionnaire. As a result, workers from three participating companies could not report information on these factors. Therefore, we performed a complete case analysis on 
a subsample $(n=461)$ where information on psychosocial work factors was also available. In this subsample analysis, we compared the results of the model with and without adjusting for the following psychosocial work factors - influence and social support at work.

\section{Results}

Out of 1119 workers consenting to participate, this study included those who were measured for at least one workday including valid accelerometer-based measurements at work, during leisure and in bed and had measurements of blood pressure yielding a final analytical sample of 669 men and women (Fig. 1). On average, workers had $2.7(\mathrm{SD}=0.9)$ valid measured days with average wear period of $23.4 \pm$ $1.3 \mathrm{~h}$ per day.

Descriptive statistics of the blue-collar workers involved in the analysis are shown in Table 1.

Additional file 1 shows the pairwise variation between physical behaviors. The variability of the ratios of the physical behaviors at work was generally higher than at leisure. Especially, at both domains, the highest variance was observed for the ratio of LPA and MVPA with sedentary time.

\section{Results of the main analysis}

The 24-h composition of time spent in physical behaviors at work and leisure was a significant predictor of SBP (crude model: $\mathrm{F}=4.75, p<0.001$; adjusted model: $\mathrm{F}=4.98, p<0.001$ ) and DBP (crude model: $\mathrm{F}=2.74, p=0.01$; adjusted model: $\mathrm{F}=2.91, p=$ $0.008)$.

Figure 2 shows the results of the compositional isotemporal reallocations based on adjusted models estimates. At both work and during leisure, reallocating time from sedentary behaviors to the remaining behaviors in that domain, was significantly and favorably (i.e., showing a reduction) associated with SBP. For example, reallocating $60 \mathrm{~min}$ from work sedentary time to the remaining work behaviors was associated with lower SBP of $-1.9(95 \% \mathrm{CI}=-3.0$ : -0.8) $\mathrm{mmHg}$, and during leisure, the same reallocation was also associated with lower SBP of -1.1 (2.1: - 0.2) mmHg.

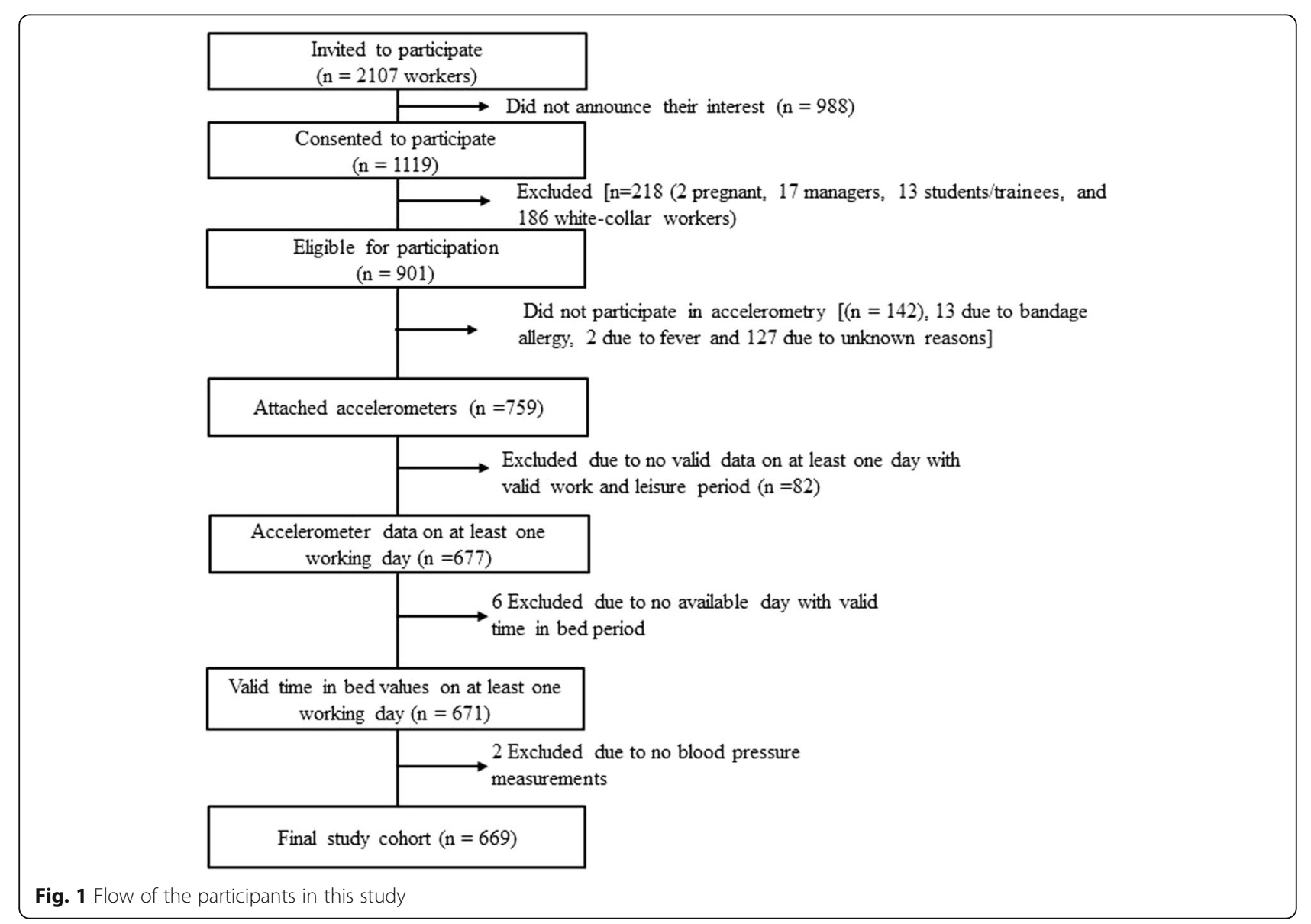


Table 1 Description of the 669 blue-collar workers included in the analyses

\begin{tabular}{|c|c|c|c|c|}
\hline Statistic & $\mathrm{N}$ & $\%$ & Mean & St. Dev. \\
\hline Age (years) & 669 & & 45.1 & 9.9 \\
\hline$\leq 45 \mathrm{yrs}$ & 306 & 46 & & \\
\hline$>45 \mathrm{yrs}$ & 363 & 54 & & \\
\hline Males & 365 & 55 & & \\
\hline \multicolumn{5}{|l|}{ Job groups } \\
\hline Cleaners & 130 & 19 & & \\
\hline Manufacturing workers & 479 & 72 & & \\
\hline Transport workers & 60 & 9 & & \\
\hline $\mathrm{BMI}\left(\mathrm{kg} / \mathrm{m}^{2}\right)$ & 656 & & 27.5 & 4.9 \\
\hline$<30$ & 481 & 73 & & \\
\hline$\geq 30$ & 175 & 27 & & \\
\hline Occupational carry/lift duration (1-6) & 667 & & 3.5 & 1.4 \\
\hline \multicolumn{5}{|l|}{ Medication intake } \\
\hline Yes & 108 & 16 & & \\
\hline No & 558 & 84 & & \\
\hline Influence at work (0-100\%) & 461 & & 61.6 & 26.5 \\
\hline $\begin{array}{l}\text { Social support at work } \\
(0-100 \%)\end{array}$ & 461 & & 78.1 & 16.5 \\
\hline Poor dietary habit (1-4) & 655 & & 2.4 & 1.2 \\
\hline Alcohol intake & 626 & & 4.4 & 6.3 \\
\hline Smokers & 197 & 30 & & \\
\hline Systolic BP (mmHg) & 669 & & 133.7 & 14.9 \\
\hline Diastolic BP (mmHg) & 669 & & 83.7 & 10.4 \\
\hline
\end{tabular}

Accelerometry-based physical behaviors; compositional means (mins/day) ${ }^{a}$ Work

\begin{tabular}{lll} 
Sedentary & 669 & 126 \\
LPA & 669 & 240 \\
MVPA & 669 & 67 \\
Leisure & & \\
Sedentary & 669 & 351 \\
LPA & 669 & 156 \\
MVPA & 669 & 44 \\
Time in bed & 669 & 456 \\
\hline
\end{tabular}

${ }^{a}$ the multivariate spread of compositional data is described in a variation matrix (Additional file 1)

For DBP, the associations were only statistically significant for reallocating leisure sedentary time to remaining leisure behaviors, and they were favorable. However, estimated differences in DBP for reallocations of the time were modest. For example, reallocating $60 \mathrm{~min}$ from leisure sedentary time to other leisure behaviors was associated with lower DBP of $-0.8(-1.5$ : -0.1$)$.
Reallocating time from LPA to other behaviors during leisure was favorably but non-statistically significant associated with SBP. For example, reallocating 60 min of leisure LPA to remaining behaviors during this domain was associated with lower SBP of -1.6 $\mathrm{mmHg}$. This reallocation during work time was weakly unfavorable and non-statistically significant. None of these associations were statistically significant for DBP.

Reallocating more time to bed from other behaviors during leisure was favorably associated with SBP. Reallocating $60 \mathrm{~min}$ more to time in bed from other leisure behaviors was associated with lower SBP of $-1.4(-2.5$ : -0.4). No statistically significant associations were observed for DBP.

Results of reallocating time between MVPA and other behaviors in both domains were statistically non-significant for both SBP and DBP.

Regarding the assumptions of the multivariate linear regression analyses, the residuals were normally distributed, there was no pattern of non-linearity in the residuals and heteroscedasticity were minimal.

\section{Results of the sensitivity analysis}

In the complete case analysis of 461 workers, we found almost identical results when we additionally adjusted for the psychosocial work factors of social support and influence at work (without additional adjustment: SBP: $\mathrm{F}=2.95, p=0.008$, DBP: $\mathrm{F}=1.91, p=0.08$; with additional adjustment: SBP: $\mathrm{F}=2.96, p=0.008, \mathrm{DBP}: \mathrm{F}=$ $1.91, p=0.08)$.

\section{Discussion}

We were the first to utilize CoDA methodology to investigate the domain-specific association between time-use composition of daily physical behaviors and blood pressure in blue collar workers. The composition of daily physical behaviors was significantly associated with SBP and DBP. At work, SBP was significantly and favorably associated (i.e. lower) with reallocating sedentary time to remaining behaviors. At leisure, similar favorable associations were observed for reallocating sedentary time to remaining behaviors, especially to time in bed. Associations with DBP were generally weak.

Reallocating sedentary time to remaining behaviors within work and leisure domains was favorably associated with SBP. We also observed similar results for DBP but only statistically significant for leisure time sedentary behavior. Overall, the favorable association of blood pressure with reducing sedentary time by increasing time in the other behaviors was similar, irrespective of domain. Specifically, we found that 


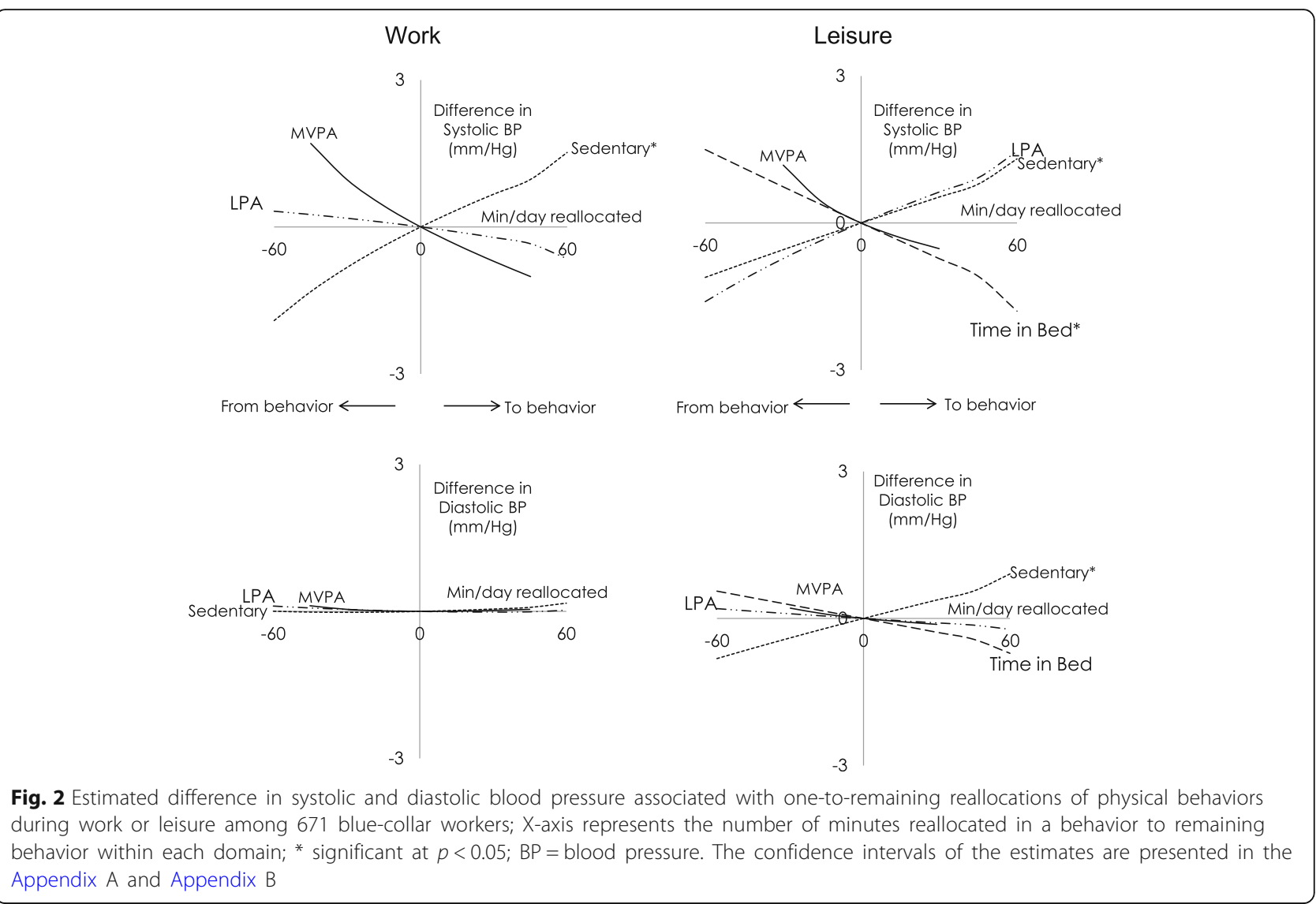

replacing $60 \mathrm{~min}$ of sedentary time at work with remaining physical behaviors was associated with almost $\approx 2 \mathrm{mmHg}$ SBP which can be interpreted to be a clinically relevant difference [37]. At leisure, this effect appeared to be smaller $(-1.1 \mathrm{mmHg})$. Numerous studies have found leisure sedentary time to be unfavorable for hypertension [6], cardiorespiratory outcomes [38] and all-cause mortality [39]. A few studies have investigated the differential associations of work and leisure sedentary time and blood pressure [14-16]. Our results are in line with some of these studies $[15,16]$. A very few studies using CoDA $[6,8,19,20]$ reported unfavorable or null associations between sedentary time (relative to other behaviors) and blood pressure. However, these studies did mostly not consider time spent in bed or asleep $[6,19]$, and none of them investigated domainspecific associations of physical behaviors and blood pressure $[6,8,19,20]$.

We observed that the results of reallocating time between MVPA and other behaviors for both domains and blood pressure were statistically non-significant. This is in contrast to previous research indicating beneficial health outcomes associated with leisure MVPA and non-beneficial health outcomes associated with work MVPA among blue-collar workers [40, 41]. A plausible reason behind non-beneficial health outcomes for MVPA at work is that it involves lifting and carrying heavy weights and awkward postures, with little possibility of breaks between activities [18]. As blue-collar workers also typically have low cardiorespiratory fitness [42], occupational MVPA may be strenuous [5, 41]. We did not observe these associations clearly, and therefore we recommend similar future studies to confirm these results.

Reallocating time to bed from other leisure behaviors was associated with lower blood pressure. Specifically, increasing time in bed by decreasing time in remaining physical behaviors at leisure was associated with a 1.4 $\mathrm{mmHg}$ decrease in SBP. This concurs with studies reporting a beneficial association between sleep duration and cardiovascular health among the general $[43,44]$ and working population [8]. Previous research among the general population has also reported a U-shaped association between sleep time and blood pressure [13]. Specifically, individuals sleeping for either $\leq 5 \mathrm{~h}$ or $>9 \mathrm{~h} /$ day are generally at risk of hypertension [13]. We did not observe this in our dataset, probably because bluecollar workers are generally engaged in physically 
strenuous jobs, possibly requiring longer recovery times during leisure compared to the general population. Similar future studies are required to confirm the linearity of associations between sleep duration (relative to other physical behaviors) and blood pressure among blue-collar workers.

Reallocating time between LPA and other behaviors during both domains were non-significantly associated with SBP and DBP. However, the corresponding estimates for leisure LPA seemed clinically relevant [37] - indicating that reallocating LPA time to other leisure behaviors tended to be associated with lower SBP. Conversely, corresponding estimates for work LPA seemed weak. The results of leisure time LPA may seem surprising as earlier work has shown that replacing the sedentary behavior with light to moderate intensity walking lowers blood pressure [11]. However, the previous overall evidence on the effects of LPA at work and leisure on blood pressure is not conclusive [41]. Due to non-significant findings of our study, we recommend conducting similar future studies to confirm our results and underline the importance of considering all domains, intensities, and postures of physical activities in a compositional manner.

The key implication of our findings points towards possible prevention of hypertension by modifying the daily time-use composition at both the work and leisure domain. The choice of reallocation strategy can be dependent on the contextual domain. For example, if it is feasible to conduct a workplace intervention, an optimum strategy may be to reallocate $60 \mathrm{~min}$ of sedentary time, a feasible and realistic change according to a previous meta-analysis on workplace interventions [45], by remaining behaviors at work (e.g. walking, non-stationary standing) and especially to MVPA at work (e.g. brisk walking, walking on stairs). At leisure, a feasible strategy may be to decrease 60 min of sedentary time by increasing time in bed or MVPA. However, when adopting these reallocation strategies, it is important to consider possible constraints during the various time-use domains. For example, it may be difficult for a cleaner to replace standing tasks with sedentary tasks at work, while it may be difficult for an individual to avoid standing (for example, cooking time) during leisure due to family commitments.

\section{Strengths and limitations}

This study is the first to use CoDA methodology to understand domain-specific time-use composition of physical behaviors. Thus our study presents an analytical base for future studies to address domain-specific associations of compositional physical behaviors with health outcomes. Another strength of our study is the device-based measurement of physical behaviors which is less erroneous and less susceptible to measurement errors than self-reports. As the devices used in this study were waterproof, workers could wear them while showering or swimming unlike in previous research [46]. Consequently, workers wore the devices for 23.4 $\pm 1.3 \mathrm{~h} /$ day. Acti4 software derives time spent in physical behaviors based on posture detections rather than on count per minute based thresholds, which have been heavily criticized for being unable to distinguish between some postures [for example sitting and standing postures [47]].

One limitation of the study is the cross-sectional design which does not allow us to make inferences about causality between time use and blood pressure. We used a conventional method to measure resting blood pressure that is a common practice in many studies and has shown to predict cardiovascular risk for mortality [48, 49]. However, resting blood pressure can be affected due to time of day, hydration level, recent mental stressors, smoking, and bouts of strenuous physical activity [50]. Therefore, ambulatory blood pressure measurements are preferable to resting blood pressure measurements [50, 51] and hence, we recommend future studies to confirm our results using ambulatory blood pressure measurements. Another limitation is the use of time in bed as a proxy for sleep. Future studies should divide time in bed into wakeful and non-wakeful periods. Our study was conducted only on blue-collar workers. Thus, the generalization of the results from this study should be made with care, especially for white-collar workers. We performed 4-day accelerometry that may, in some cases, not capture the usual physical activity of the participants. However, a number of studies have suggested that 4-day accelerometry is sufficient to reliably estimate habitual time spent in various physical behaviors $[52,53]$. Additionally, we cannot ignore the fact that there may be residual confounding due to unmeasured factors.

\section{Conclusion}

Time-use composition of various physical behaviors at work and leisure and time in bed was associated with SBP and DBP. At work, favorable associations were observed when sedentary time was reallocated to remaining behaviors. During leisure, it seems beneficial to reallocate time from sedentary behavior to remaining behaviors, especially to time in bed. Behavioral modification strategies based on reallocations of time within the composition of physical behaviors at work and leisure provide useful knowledge for the prevention of hypertension, especially among this high-risk group of lower socioeconomic blue-collar workers. 


\section{Appendix A}

Table 2 Estimated difference in systolic blood pressure (95\% confidence intervals) associated with one-to-remaining reallocations of physical behaviors at work or leisure among 671 blue-collar workers

\begin{tabular}{|c|c|c|c|c|c|c|c|c|}
\hline \multirow{2}{*}{$\begin{array}{l}\text { Difference in } \\
\text { behavior (min/day) }\end{array}$} & \multicolumn{8}{|c|}{ Estimated difference in SBP $(\mathrm{mmHg})(95 \% \mathrm{Cl})$} \\
\hline & \multicolumn{2}{|c|}{ Sedentary to remaining $^{a}$} & \multicolumn{2}{|c|}{ LPA to remaining $^{a}$} & \multicolumn{2}{|c|}{ MVPA to remaining ${ }^{a}$} & \multicolumn{2}{|c|}{ Time in bed to remaining ${ }^{a}$} \\
\hline-90 & -3.6 & $(-5.8:-1.4)$ & 0.4 & $(-1.6: 2.4)$ & & & & \\
\hline-75 & -2.6 & $(-4.2:-1.1)$ & 0.4 & $(-1.3: 2.0)$ & & & & \\
\hline-60 & -1.9 & $(-3.0:-0.8)$ & 0.3 & $(-1.0: 1.6)$ & & & & \\
\hline-45 & -1.3 & $(-2.1:-0.5)$ & 0.3 & $(-0.7: 1.2)$ & 1.7 & $(-1.4: 4.8)$ & & \\
\hline-30 & -0.8 & $(-1.3:-0.3)$ & 0.2 & $(-0.5: 0.8)$ & 1.0 & $(-0.7: 2.6)$ & & \\
\hline-15 & -0.4 & $(-0.6:-0.2)$ & 0.1 & $(-0.2: 0.4)$ & 0.4 & $(-0.3: 1.2)$ & & \\
\hline 0 & 0.0 & $(0.0: 0.0)$ & 0.0 & $(0.0: 0.0)$ & 0.0 & $(0.0: 0.0)$ & & \\
\hline 15 & 0.4 & $(0.1: 0.6)$ & -0.1 & $(-0.4: 0.2)$ & -0.4 & $(-1.0: 0.2)$ & & \\
\hline 30 & 0.7 & $(0.3: 1.1)$ & -0.2 & $(-0.9: 0.5)$ & -0.7 & $(-1.8: 0.4)$ & & \\
\hline 45 & 1.0 & $(0.4: 1.6)$ & -0.3 & $(-1.4: 0.7)$ & -1.0 & $(-2.6: 0.6)$ & & \\
\hline 60 & 1.3 & $(0.5: 2.0)$ & -0.5 & $(-1.9: 0.9)$ & & & & \\
\hline 75 & 1.5 & $(0.5: 2.5)$ & -0.6 & $(-2.5: 1.2)$ & & & & \\
\hline 90 & 1.8 & $(0.6: 2.9)$ & -0.8 & $(-3.1: 1.5)$ & & & & \\
\hline \multicolumn{9}{|l|}{ Leisure } \\
\hline-90 & -1.7 & $(-3.2:-0.2)$ & -2.8 & $(-5.8: 0.3)$ & & & 2.3 & $(0.7: 3.9)$ \\
\hline-75 & -1.4 & $(-2.6:-0.2)$ & -2.1 & $(-4.5: 0.2)$ & & & 1.9 & $(0.6: 3.2)$ \\
\hline-60 & -1.1 & $(-2.1:-0.2)$ & -1.6 & $(-3.4: 0.2)$ & & & 1.5 & $(0.4: 2.6)$ \\
\hline-45 & -0.8 & $(-1.5:-0.1)$ & -1.1 & $(-2.4: 0.1)$ & & & 1.1 & $(0.3: 1.9)$ \\
\hline-30 & -0.5 & $(-1.0:-0.1)$ & -0.7 & $(-1.5: 0.1)$ & 1.2 & $(-2.0: 4.4)$ & 0.7 & $(0.2: 1.3)$ \\
\hline-15 & -0.3 & $(-0.5: 0.0)$ & -0.3 & $(-0.7: 0.0)$ & 0.4 & $(-0.7: 1.6)$ & 0.4 & $(0.1: 0.6)$ \\
\hline 0 & 0.0 & $(0.0: 0.0)$ & 0.0 & $(0.0: 0.0)$ & 0.0 & $(0.0: 0.0)$ & 0.0 & $(0.0: 0.0)$ \\
\hline 15 & 0.3 & $(0.0: 0.5)$ & 0.3 & $(0.0: 0.7)$ & -0.3 & $(-1.1: 0.5)$ & -0.4 & $(-0.6:-0.1)$ \\
\hline 30 & 0.5 & $(0.1: 1.0)$ & 0.6 & $(0.0: 1.3)$ & -0.5 & $(-2.0: 1.0)$ & -0.7 & $(-1.2:-0.2)$ \\
\hline 45 & 0.8 & $(0.1: 1.5)$ & 0.9 & $(-0.1: 1.9)$ & & & -1.1 & $(-1.8:-0.3)$ \\
\hline 60 & 1.1 & $(0.2: 2.0)$ & 1.2 & $(-0.1: 2.5)$ & & & -1.4 & $(-2.5:-0.4)$ \\
\hline 75 & 1.3 & $(0.2: 2.4)$ & 1.5 & $(-0.1: 3.0)$ & & & -1.8 & $(-3.1:-0.5)$ \\
\hline 90 & 1.6 & $(0.2: 2.9)$ & 1.7 & $(-0.1: 3.5)$ & & & -2.2 & $(-3.7:-0.6)$ \\
\hline
\end{tabular}

Results in bold are considered statistically significant because the confidence interval did not include 0 . ${ }^{\text {a }}$ remaining means those behaviors besides one which is getting replaced within each domain. For example sedentary to remaining at work means reallocation between sedentary time and time spent on LPA and MVPA at work. Similarly, MVPA to remaining at leisure means reallocations between MVPA time and time spent on LPA, sedentary and in bed. LPA $=$ light physical activity, MVPA = moderate-to-vigorous physical activity 


\section{Appendix B}

Table 3 Estimated difference in diastolic blood pressure (95\% confidence intervals) associated with one-to-remaining reallocations of physical behaviors at work or leisure among 671 blue-collar workers

\begin{tabular}{|c|c|c|c|c|c|c|c|c|}
\hline \multirow{2}{*}{$\begin{array}{l}\text { Difference in } \\
\text { behavior (min/day) }\end{array}$} & \multicolumn{8}{|c|}{ Estimated difference in DBP $(\mathrm{mmHg})(95 \% \mathrm{Cl})$} \\
\hline & \multicolumn{2}{|c|}{ Sedentary to remaining ${ }^{a}$} & \multicolumn{2}{|c|}{ LPA to remaining $^{a}$} & \multicolumn{2}{|c|}{ MVPA to remaining $^{a}$} & \multicolumn{2}{|c|}{ Time in bed to remaining } \\
\hline \multicolumn{9}{|l|}{ Work } \\
\hline-90 & 0.1 & $(-1.5: 1.7)$ & 0.2 & $(-1.2: 1.7)$ & & & & \\
\hline-75 & 0 & $(-1.1: 1.2)$ & 0.2 & $(-1: 1.3)$ & & & & \\
\hline-60 & 0 & $(-0.8: 0.8)$ & 0.1 & $(-0.8: 1)$ & & & & \\
\hline-45 & 0 & $(-0.6: 0.5)$ & 0.1 & $(-0.6: 0.8)$ & 0.1 & $(-2.1: 2.3)$ & & \\
\hline-30 & 0 & $(-0.4: 0.3)$ & 0 & $(-0.4: 0.5)$ & 0 & $(-1.2: 1.2)$ & & \\
\hline-15 & 0 & $(-0.2: 0.1)$ & 0 & $(-0.2: 0.3)$ & 0 & $(-0.5: 0.5)$ & & \\
\hline 0 & 0 & $(0: 0)$ & 0 & $(0: 0)$ & 0 & $(0: 0)$ & & \\
\hline 15 & 0 & $(-0.1: 0.2)$ & 0 & $(-0.2: 0.2)$ & 0 & $(-0.4: 0.4)$ & & \\
\hline 30 & 0 & $(-0.2: 0.3)$ & 0 & $(-0.5: 0.5)$ & 0 & $(-0.8: 0.8)$ & & \\
\hline 45 & 0.1 & $(-0.3: 0.5)$ & 0 & $(-0.8: 0.7)$ & 0 & $(-1.1: 1.2)$ & & \\
\hline 60 & 0.2 & $(-0.5: 0.9)$ & 0 & $(-1.3: 1.3)$ & & & & \\
\hline 75 & 0.1 & $(-0.4: 0.7)$ & 0 & $(-1: 1)$ & & & & \\
\hline 90 & 0.2 & $(-0.6: 1.1)$ & 0.1 & $(-1.6: 1.7)$ & & & & \\
\hline \multicolumn{9}{|l|}{ Leisure } \\
\hline-90 & -1.3 & $(-2.3:-0.2)$ & 0.3 & $(-1.9: 2.5)$ & & & 0.8 & $(-0.3: 2)$ \\
\hline-75 & -1 & $(-1.9:-0.2)$ & 0.3 & $(-1.4: 1.9)$ & & & 0.7 & $(-0.3: 1.6)$ \\
\hline-60 & -0.8 & $(-1.5:-0.1)$ & 0.2 & $(-1.1: 1.5)$ & & & 0.6 & $(-0.2: 1.3)$ \\
\hline-45 & -0.6 & $(-1.1:-0.1)$ & 0.1 & $(-0.7: 1)$ & & & 0.4 & $(-0.1: 1)$ \\
\hline-30 & -0.4 & $(-0.7:-0.1)$ & 0.1 & $(-0.5: 0.7)$ & 0.2 & $(-2.1: 2.5)$ & 0.3 & $(-0.1: 0.7)$ \\
\hline-15 & -0.2 & $(-0.4: 0)$ & 0 & $(-0.2: 0.3)$ & 0.1 & $(-0.8: 0.9)$ & 0.1 & $(0: 0.3)$ \\
\hline 0 & 0 & $(0: 0)$ & 0 & $(0: 0)$ & 0 & $(0: 0)$ & 0 & $(0: 0)$ \\
\hline 15 & 0.2 & $(0: 0.4)$ & 0 & $(-0.3: 0.2)$ & -0.1 & $(-0.7: 0.5)$ & -0.1 & $(-0.3: 0)$ \\
\hline 30 & 0.4 & $(0.1: 0.7)$ & -0.1 & $(-0.6: 0.4)$ & -0.1 & $(-1.2: 0.9)$ & -0.3 & $(-0.6: 0.1)$ \\
\hline 45 & 0.6 & $(0.1: 1)$ & -0.1 & $(-0.8: 0.6)$ & & & -0.4 & $(-1: 0.1)$ \\
\hline 60 & 0.7 & $(0.1: 1.4)$ & -0.2 & $(-1.1: 0.7)$ & & & -0.6 & $(-1.3: 0.2)$ \\
\hline 75 & 0.9 & $(0.1: 1.7)$ & -0.2 & $(-1.3: 0.9)$ & & & -0.7 & $(-1.6: 0.2)$ \\
\hline 90 & 1.1 & $(0.1: 2)$ & -0.3 & $(-1.6: 1)$ & & & -0.9 & $(-1.9: 0.2)$ \\
\hline
\end{tabular}

Results in bold are considered statistically significant because the confidence interval did not include $0 .{ }^{a}$ remaining means those behaviors besides one which is getting replaced within each domain. For example sedentary to remaining at work means reallocation between sedentary time and time spent on LPA and MVPA at work. Similarly, MVPA to remaining at leisure means reallocations between MVPA time and time spent on LPA, sedentary and in bed. LPA $=$ light physical activity, MVPA = moderate-to-vigorous physical activity.

\section{Additional file}

Additional file 1: Variation matrix showing the variation of each physical behavior relative to remaining behaviors at work and leisure domains among 671 blue-collar workers. (DOCX $13 \mathrm{~kb}$ )

Additional file 2: STROBE Statement-checklist of items that should be included in reports of observational studies. (DOCX 22 kb)

\section{Abbreviations}

BMl: Body mass index; CoDA: Compositional data analysis; DBP: Diastolic blood pressure; LPA: Light physical activity; MVPA: Moderate-to-vigorous physical activity; SBP: Systolic blood pressure
Acknowledgments

We would like to thank Marie Brik Jørgensen — one of the principal investigators of DPHACTO - and the entire DPHACTO research group at the National Research Centre for the Working Environment, Copenhagen, Denmark.

\section{Funding}

This study was financially supported by the Danish Work Environment Research Fund (journal number 01-2015-03). The DPHACTO cohort is partly supported by a grant from the Danish government named 'satspulje'.

\section{Availability of data and materials}

The datasets used and/or analysed during the current study are available from the corresponding author on reasonable request. 


\section{Authors' contributions}

All authors have contributed in planning, designing, analyzing and finalizing the manuscript. Andreas Holtermann was the principal investigator of DPHACTO cohort data used in this study. Nidhi Gupta originated the idea for this study. Nidhi Gupta, Mette Korshøj and Dorothea Dumuid were responsible for the statistical analyses. Nidhi Gupta was responsible for analyzing and interpreting the data and writing the first draft of the manuscript. All authors have edited, reviewed, and approved drafts of this manuscript, including the final version. All authors take full responsibility for and have read and approved this final version of this manuscript.

\section{Ethics approval and consent to participate}

All workers provided written informed consent prior to participation. The study was conducted according to the Helsinki declaration and approved by the local Ethics Committee (The Capital Region of Denmark, H-2-2012-011).

\section{Consent for publication}

We did not include any individual person's data in any form in this manuscript.

\section{Competing interests}

The authors declare that they have no competing interests.

\section{Publisher's Note}

Springer Nature remains neutral with regard to jurisdictional claims in published maps and institutional affiliations.

\begin{abstract}
Author details
${ }^{1}$ National Research Centre for the Working Environment, Copenhagen, Denmark. ${ }^{2}$ Alliance for Research in Exercise, Nutrition, and Activity (ARENA), School of Health Sciences, University of South Australia, Adelaide, South Australia, Australia. ${ }^{3}$ Department of Public and Occupational Health, Amsterdam Public Health Research Institute, VU University Medical Center, Amsterdam, The Netherlands. ${ }^{4}$ Center for Clinical Research and Prevention, Bispebjerg and Frederiksberg Hospital, The Capital Region, Copenhagen, Denmark. ${ }^{5}$ Department of Sports Science and Clinical Biomechanics, University of Southern Denmark, Odense, Denmark.
\end{abstract}

\section{Received: 22 October 2018 Accepted: 26 December 2018} Published online: 10 January 2019

\section{References}

1. Gaziano TA, Bitton A, Anand S, Weinstein MC. The global cost of nonoptimal blood pressure. J Hypertens. 2009;27(7):1472-7.

2. Forouzanfar MH, Liu P, Roth GA, Ng M, Biryukov S, Marczak L, et al. Global burden of hypertension and systolic blood pressure of at least 110 to 115 mm hg, 1990-2015. JAMA. 2017;317(2):165-82.

3. Kearney PM, Whelton M, Reynolds K, Muntner P, Whelton PK, He J. Global burden of hypertension: analysis of worldwide data. Lancet. 2005;365(9455): 217-23.

4. Krause N, Brand RJ, Arah OA, Kauhanen J. Occupational physical activity and 20-year incidence of acute myocardial infarction: results from the Kuopio ischemic heart disease risk factor study. Scand J Work Environ Health. 2015; 41(2):124-39.

5. Clays E, De Bacquer D, Van Herck K, De Backer G, Kittel F, Holtermann A. Occupational and leisure time physical activity in contrasting relation to ambulatory blood pressure. BMC Public Health. 2012;12:1002.

6. Chastin SF, Palarea-Albaladejo J, Dontje ML, Skelton DA. Combined effects of time spent in physical activity, sedentary behaviors and sleep on obesity and cardio-metabolic health markers: a novel compositional data analysis approach. PLoS One. 2015;10(10):e0139984.

7. Whelton SP, Chin A, Xin X, He J. Effect of aerobic exercise on blood pressure: a meta-analysis of randomized, controlled trials. Ann Intern Med. 2002;136(7):493-503.

8. Gupta N, Dumuid D, Korshøj M, Jørgensen M, Søgaard K, Holtermann A. Is daily movement behaviors' composition related to blood pressure in working adults? Medicine and Science in Sports and Exercise. 2018;in press.

9. Lee PH, Wong FK. The association between time spent in sedentary behaviors and blood pressure: a systematic review and meta-analysis. Sports Med. 2015;45(6):867-80.
10. Diaz KM, Shimbo D. Physical activity and the prevention of hypertension. Curr Hypertens Rep. 2013;15(6):659-68.

11. Larsen RN, Kingwell BA, Sethi P, Cerin E, Owen N, Dunstan DW. Breaking up prolonged sitting reduces resting blood pressure in overweight/obese adults. Nutrition, metabolism, and cardiovascular diseases : NMCD. 2014;24(9):976-82.

12. Pal S, Radavelli-Bagatini $\mathrm{S}, \mathrm{Ho}$ S. Potential benefits of exercise on blood pressure and vascular function. J Am Soc Hypertens. 2013;7(6):494-506.

13. Wang $Y$, Mei H, Jiang Y-R, Sun W-Q, Song Y-J, Liu S-J, et al. Relationship between duration of sleep and hypertension in adults: a meta-analysis. J Clin Sleep Med. 2015;11(9):1047-56.

14. Pesola AJ, Laukkanen A, Heikkinen R, Sipila S, Saakslahti A, Finni T. Accelerometer-assessed sedentary work, leisure time and cardio-metabolic biomarkers during one year: effectiveness of a cluster randomized controlled trial in parents with a sedentary occupation and young children. PLoS One. 2017;12(8):e0183299.

15. Katzmarzyk PT, Church TS, Craig CL, Bouchard C. Sitting time and mortality from all causes, cardiovascular disease, and cancer. Med Sci Sports Exerc. 2009:41(5):998-1005.

16. Mainsbridge CP, Cooley PD, Fraser SP, Pedersen SJ. The effect of an e-health intervention designed to reduce prolonged occupational sitting on mean arterial pressure. J Occup Environ Med. 2014;56(11):1189-94.

17. Holtermann A, Hansen JV, Burr H, Søgaard K, Sjøgaard G. The health paradox of occupational and leisure-time physical activity. Br J Sports Med. 2012;46(4):291-5.

18. Holtermann A, Krause N, van der Beek AJ, Straker L. The physical activity paradox: six reasons why occupational physical activity (OPA) does not confer the cardiovascular health benefits that leisure time physical activity does. Br J Sports Med. 2017;52(3):149-50.

19. Winkler EA, Chastin S, Eakin EG, Owen N, LaMontagne AD, Moodie M, et al. Cardiometabolic impact of changing sitting, standing, and stepping in the workplace. Med Sci Sports Exerc. 2017;50(3):516-24.

20. Dumuid D, Lewis LK, Olds TS, Maher C, Bondarenko C, Norton L. Relationships between older adults' use of time and cardio-respiratory fitness, obesity and cardio-metabolic risk: a compositional isotemporal substitution analysis. Maturitas. 2018;110:104-10.

21. Medina C, Janssen I, Barquera S, Bautista-Arredondo S, González ME, González C. Occupational and leisure time physical inactivity and the risk of type II diabetes and hypertension among Mexican adults: a prospective cohort study. Sci Rep. 2018;8(1):5399.

22. Li J, Loerbroks A, Angerer P. Physical activity and risk of cardiovascular disease: what does the new epidemiological evidence show? Curr Opin Cardiol. 2013;28(5):575-83.

23. Gupta N, Christiansen CS, Hanisch C, Bay H, Burr H, Holtermann A. Is questionnaire-based sitting time inaccurate and can it be improved? A cross-sectional investigation using accelerometer-based sitting time. BMJ Open. 2017;7(1):e013251.

24. Gupta N, Heiden M, Mathiassen SE, Holtermann A. Is self-reported time spent sedentary and in physical activity differentially biased by age, gender, body mass index, and low-back pain? Scand J work environ health; 2017.

25. Hallman DM, Mathiassen SE, Gupta N, Korshoj M, Holtermann A. Differences between work and leisure in temporal patterns of objectively measured physical activity among blue-collar workers. BMC Public Health. 2015;15(1):976.

26. Jørgensen MB, Korshøj M, Lagersted-Olsen J, Villumsen M, Mortensen OS, Skotte J, et al. Physical activities at work and risk of musculoskeletal pain and its consequences: protocol for a study with objective field measures among blue-collar workers. BMC Musculoskel Disord. 2013;14:213. https:// doi.org/10.1186/1471-2474-14-213.

27. Gupta N, Stordal CC, Hallman D, Korshøj M, Gomes Cl, Holtermann A. Is objectively measured sitting time associated with low back pain? A crosssectional investigation in the NOMAD study. PLoS One. 2015;10(3):e0121159.

28. Skotte J, Korshoj M, Kristiansen J, Hanisch C, Holtermann A. Detection of physical activity types using triaxial accelerometers. J Phys Act Health. 2014; 11(1):76-84

29. Gupta N, Heiden M, Aadahl M, Korshoj M, Jorgensen MB, Holtermann A. What is the effect on obesity indicators from replacing prolonged sedentary time with brief sedentary bouts, standing and different types of physical activity during working days? A cross-sectional accelerometer-based study among blue-collar workers. PLoS One. 2016;11(5):e0154935.

30. Clays E, De Bacquer D, Janssens H, De Clercq B, Casini A, Braeckman L, et al. The association between leisure time physical activity and coronary heart 
disease among men with different physical work demands: a prospective cohort study. Eur J Epidemiol. 2013;28(3):241-7.

31. Law MR, Morris JK, Wald NJ. Use of blood pressure lowering drugs in the prevention of cardiovascular disease: meta-analysis of 147 randomised trials in the context of expectations from prospective epidemiological studies. BMJ. 2009;338.

32. Hallman DM, Gupta N, Heiden M, Mathiassen SE, Korshøj M, Jørgensen MB, et al. Is prolonged sitting at work associated with the time course of neck-shoulder pain? A prospective study in Danish blue-collar workers. BMJ Open. 2016;6(11): e012689.

33. van den Boogaart GK, Tolosana R, Bren M. Compositions: Compositional Data Analysis (R package). R (version $\geq 220) 2014$

34. Pedisic Z. Measurement issues and poor adjustments for physical activity and sleep undermine sedentary behaviour research - the focus should shift to the balance between sleep, sedentary behaviour, standing and activity. Kinesiology. 2014:46(1):135-46.

35. Dumuid D, Stanford TE, Martin-Fernandez JA, Pedisic Z, Maher CA, Lewis LK, et al. Compositional data analysis for physical activity, sedentary time and sleep research. Stat Methods Med Res. 2017. https://doi.org/10.1177/ 0962280217710835

36. Pedišić Ž, Dumuid D, Olds T. Integrating sleep, sedentary behaviour, and physical activity research in the emerging field of time-use epidemiology: definitions, concepts, statistical methods, theoretical framework, and future directions. Kinesiology. 2017:49(2):1-18.

37. Lewington S, Clarke R, Qizilbach N, Peto R, Collins R. Age-specific relevance of usual blood pressure to vascular mortality: a meta-analysis of individual data for one million adults in 61 prospective studies. Lancet. 2002;360:1903-13.

38. Rezende LF, Rodrigues Lopes M, Rey-Lopez JP, Matsudo VK, Luiz OC. Sedentary behavior and health outcomes: an overview of systematic reviews. PLoS One. 2014;9:e105620.

39. Evenson KR, Herring AH, Wen F. Accelerometry-assessed latent class patterns of physical activity and sedentary behavior with mortality. Am J Prev Med. 2017;52(2):135-43.

40. Korshøj M, Lidegaard M, Kittel F, Van Herck K, De Backer G, De Bacquer D, et al. The relation of ambulatory heart rate with all-cause mortality among middle-aged men: a prospective cohort study. PLoS One. 2015;10(3): e0121729.

41. Allesøe K, Holtermann A, Aadahl M, Thomsen JF, Hundrup YA, Søgaard K. High occupational physical activity and risk of ischaemic heart disease in women: the interplay with physical activity during leisure time. Eur J Prev Cardiol. 2014;22(12):1601-8.

42. Holtermann A, Marott JL, Gyntelberg F, Sogaard K, Suadicani P, Mortensen OS, et al. Occupational and leisure time physical activity: risk of all-cause mortality and myocardial infarction in the Copenhagen City Heart Study. A prospective cohort study. BMJ Open. 2012;2(1):e000556.

43. Calhoun DA, Harding SM. Sleep and Hypertension. Chest. 2010;138(2):434-43.

44. Gangwisch JE. A review of evidence for the link between sleep duration and hypertension. Am J Hypertens. 2014;27(10):1235-42.

45. Chu AH, Ng SH, Tan CS, Win AM, Koh D, Muller-Riemenschneider F. A systematic review and meta-analysis of workplace intervention strategies to reduce sedentary time in white-collar workers. Obes Rev. 2016;17(5):467-81

46. Vanhelst J, Béghin L, Drumez E, Coopman S, Gottrand F. Awareness of wearing an accelerometer does not affect physical activity in youth. BMC Med Res Methodol. 2017;17:99.

47. Atkin AJ, Gorely T, Clemes SA, Yates T, Edwardson C, Brage S, et al. Methods of measurement in epidemiology: sedentary behaviour. Int J Epidemiol. 2012;41(5):1460-71.

48. Koh AS, Talaei M, Pan A, Wang R, Yuan J-M, Koh W-P. Systolic blood pressure and cardiovascular mortality in middle-aged and elderly adults - the Singapore Chinese health study. Int J Cardiol. 2016;219:404-9.

49. Brown DW, Giles WH, Greenlund KJ. Blood pressure parameters and risk of fatal stroke, NHANES II mortality study. Am J Hypertens. 2007;20(3):338-41.

50. Hansen TW, Kikuya M, Thijs L, Bjorklund-Bodegard K, Kuznetsova T, Ohkubo $T$, et al. Prognostic superiority of daytime ambulatory over conventional blood pressure in four populations: a meta-analysis of 7030 individuals. J Hypertens. 2007;25(8):1554-64.

51. Eiskjaer $\mathrm{H}$, Pedersen EB. The relationship between casual and ambulatory blood pressure in essential hypertension: the influence of work, duration of hypertension and antihypertensive treatment. J Intern Med. 1989;225(3):165-72.
52. Hart TL, Swartz AM, Cashin SE, Strath SJ. How many days of monitoring predict physical activity and sedentary behaviour in older adults? The international journal of behavioral nutrition and physical activity. Int J Behav Nutr Phys Act. 2011;8:62

53. Kocherginsky M, Huisingh-Scheetz M, Dale W, Lauderdale DS, Waite L. Measuring Physical Activity with Hip Accelerometry among U.S. Older Adults: How Many Days Are Enough? PLoS ONE. 2017;12(1):e0170082.

\section{Ready to submit your research? Choose BMC and benefit from:}

- fast, convenient online submission

- thorough peer review by experienced researchers in your field

- rapid publication on acceptance

- support for research data, including large and complex data types

- gold Open Access which fosters wider collaboration and increased citations

- maximum visibility for your research: over $100 \mathrm{M}$ website views per year

At BMC, research is always in progress.

Learn more biomedcentral.com/submissions 